\title{
Carta de Salvador
}

A asma é uma doença crônica que compromete $10 \%$ da população brasileira, sendo responsável, anualmente, por 400.000 internações hospitalares, 2.000 óbitos, incontáveis assistências ambulatoriais, principalmente nas emergências, e um grande absenteísmo ao trabalho e à escola.

A asma ocorre por uma interação entre fatores hereditários e ambientais, havendo uma inflamação crônica das vias aéreas e, nas crises, os pacientes manifestam falta de ar, tosse, chiado e aperto no peito, podendo apresentar grande sofrimento e, mesmo, vir a morrer como conseqüência da doença. Embora os sintomas costumem iniciar nos primeiros anos de vida, podem surgir pela primeira vez em qualquer idade.

0 tratamento da asma é feito basicamente por medicamentos antiinflamatórios (geralmente, esteróides inalatórios) para manutenção e por broncodilatadores (geralmente, beta2-adrenérgicos inalatórios de efeito rápido) para as crises.

Apesar de todos os avanços científicos e do surgimento de remédios eficazes, a doença continua aumentando sua prevalência e mortalidade, isto ocorrendo, em grande parte, devido à não existência de um programa assistencial efetivo.

Como solução para o problema, o Ministério da Saúde (MS) elaborou o Programa Nacional de Controle da Asma (PNCA), em colaboração com as Sociedades Brasileiras de Especialidades (Pneumologia e Tisiologia, Pediatria, Alergia e Imunopatologia, e Clínica Médica), tendo assinado em 9 de dezembro de 1999 a portaria que 0 instituiu oficialmente.

O PNCA visa a organizar, implantar e manter a assistência dos pacientes asmáticos através do Sistema Único de Saúde (SUS), utilizando para isto tanto os recursos próprios dos locais de assistência quanto os provenientes do MS.

Através deste documento, denominado CARTA DE SALVADOR, aprovado em Assembléia durante O III CONGRESSO BRASILEIRO DE ASMA, realizado em Salvador (BA), de 2 a 4 de agosto de 2001, as Sociedades Brasileiras de Pneumologia e Tisiologia, de Pediatria, de Alergia e Imunopatologia, e de Clínica Médica, e todos os seus 50.000 membros - pneumologistas, pediatras, alergistas e clínicos - manifestam ao Senhor Ministro da Saúde, J osé Serra, a necessidade da implantação imediata do Programa Nacional de Controle da Asma.

Salvador/BA, 4 de agosto de 2001.

DR. LUIZ CARLOS CORRÊA dA SILVA

Presidente da Sociedade Brasileira de Pneumologia e Tisiologia

DR. LINCOLN MARCELO Freire

Presidente da Sociedade Brasileira de Pediatria

Dr. Nelson Figueiredo Mendes

Presidente da Sociedade Brasileira de Alergia e Imunopatologia

Dr. Antônio Carlos Lopes

Presidente da Sociedade Brasileira de Clínica Médica

Dr. Álvaro Cruz

Presidente do III Congresso Brasileiro de Asma 